\title{
Renalase as a Biomarker in Gestations with Preeclampsia
}

\author{
Heba Abdelbasset Allam ${ }^{1 *}$ and Dalal Elsayed Abdelaal ${ }^{2}$ \\ ${ }^{1}$ Obstetrics and Gynecology Department, Ain Shams University, Egypt \\ ${ }^{2}$ Clinical Pathology Department, Ain Shams University, Egypt
}

Submission: August 20, 2018; Published: September 07, 2018

"Corresponding author: Heba Abdelbasset Allam, Lecturer in department of Obstetrics and Gynecology, Ain Shams University, Ain Shams Maternity Hospital, Egypt; Email: hebaa_abdbaset@yahoo.com

\section{Abstract}

Background: Preeclampsia is clinically featured by a rise in high blood pressure and reduction in glomerular filtration rate and protein excretion in urine, on the other hand, the fundamental pathophysiological pathways are un clarified. Renalase as a biological marker is a newly revealed protein concerned in manipulation and adjustment of blood pressure levels in human physiology.

Methodology: serum plasma levels of renalase were assayed in healthy Gestations, and gestations with mild and severe PET matched for subject age, gestational age, in the third gestational trimester. Serum renalase levels have been compared in gestations with mild, severe preeclampsia and without preeclampsia gestations as controls. Other laboratory parameters and indices have been assessed and evaluated in correlation with serum renalase.

Results: In healthy gestations serum levels of renalase were statistically significantly higher than in mild and severe preeclampsia cases. Serum levels of renalase had an inverse correlation with blood pressure measurement levels and had a positive correlation with glomerular filtration rate.

Conclusion: The results displayed that the pathophysiological development of preeclampsia in gestations is linked with alteration in levels of serum renalase. Elevated blood pressure levels and renal damage that feature this pathological disorder is impacted by low serum levels of renalase.

Keywords: Preeclampsia; Hypertension; Renalase

\section{Introduction}

Gestation is featured by physiologic adaptations within systemic and renal hemodynamic systems. The initial hemodynamic adaptation in gestation is crucial systemic arterial vasodilatory physiological change [1]. On the other hand, hypertensive illnesses involve up to $10 \%$ of all gestations [2]. Preeclampsia the chief and most prominent hypertensive illness of gestation is the most common etiology and cause of various fetal and maternal clinical morbidity and mortality. Even though the clinical effect of the preeclampsia, management protocols of that disorder did not change significantly. This could be due to unclear pathophysiologic pathways of the disease. It is described by raised systemic arterial resistance levels. Failure of vascular refractoriness physiological feature to vasoconstricting agents contribute to the systemic occurrence of vascular vasoconstriction in preeclampsia [3]. A new hypothetical feature that has implied and investigated to elucidate the rise in blood pressure levels in gestations that have hyperadrenergic status may donate to the pathological pathway of preeclampsia. Prior research studies displayed that amplified sympathetic vasoconstricting effect is cornerstone pathological mechanism at vascular system level causing a raised vascular resistance [4-6]. Renalase is a variety of monoamine oxidase enzyme and it acts directly to degrade catecholamines (noradrenaline, adrenaline and dopamine). It reduces the blood pressure levels in vivo by inhibiting cardiac contractility feature and heart rate and blocking the compensatory mechanism rise in peripheral levels of vascular tone $[7,8]$. Consequently serum renalase is considered as a novel biological marker for primary hypertensive disease. It is secreted into the blood by the renal system. Up to date research studies have additionally displayed and revealed that renalase is secreted and synthesized within the peripheral nervous system, hypothalamus and the pituitary [9]. In an experimental research study, renalase expressive features is augmented in ovaries during gestation [10]. In the current research study the main goal to investigate the serum levels of renalase levels in clinically normal gestations and correlations between serum levels of renalase and blood pressure levels, glomerular filtration rate and protein excretion in urine in gestations with mild and severe preeclampsia [11]. 


\section{Methodology}

The total cohort recruited for the research, 150 gestations having an age range between 20-39 yrs (50 normotensive gestations, 50 gestations with mild preeclampsia and 50 gestations with severe preeclampsia) were enrolled for the research study. Preeclamptic gestations (10) with a protein excreted in urine $>300 \mathrm{mg} / \mathrm{l}$ collected at random or $>300 \mathrm{mg} / 24$ $\mathrm{h}$ after 20 gestational weeks were recruited in the research study for estimation of GFR the following equation has been used

$$
\operatorname{GFR}\left(\mathrm{mL} / \mathrm{min} / 1.73 \mathrm{~m}^{2}\right)=175 \times\left(\mathrm{S}_{\mathrm{cr}}\right)^{-1.154} \times(\text { Age })^{-0.203} \times(0.742) .
$$

Small for Gestational Age was described as a birth weight under the $10^{\text {th }}$ centile for gestational age by fetal growth charts (11). Mean gestational age of gestations with mild preeclampsia was $35 \pm 2$ gestational weeks with severe preeclampsia had a mean gestational age of $34 \pm 3$ gestational weeks. The 40 normotensive gestations were recruited from outpatient clinics according to inclusive research criteria (gestation age above 20 weeks); and exclusive research criteria ((1) history of preeclampsia in prior gestations; (2) history of hypertension and renal disorders; (3) history of cardiovascular disorders). Mean gestational age of normal gestations have been $34 \pm 3$ weeks. The demographic research subjects' criteria (age, history of hypertensive disorders and preeclampsia, gestational weeks, BMI) of the whole research cohort was obtained at the start of the current research study.

Serum levels of creatinine, albumin, and uric acid levels of gestations were obtained from hospital filing system. The research study performance has been approved by the Ain Shams Maternity Hospital Ethical Committee and a written research consent was obtained from each research study subject.

Blood samples have been collected and centrifuged at 1000 $\times \mathrm{g}$ for 10 minutes. Serum levels of renalase were assayed by usage of ELISA kit for renalase. (Aviva Systems Biology RNLS ELISA Kit (Human) (OKEH00771) is based on standard sandwich enzyme-linked immuno-sorbent assay technology. An antibody specific for RNLS has been pre-coated onto a 96well plate (12 8 Well Strips). Standards or test samples are Result

Table 1: $p$-values for ANOVA test, ${ }^{* *} p$-value for Mann Whitney $U$ or $T$ test, ${ }^{* \star *}{ }^{2}$ test PE: preeclampsia; BMI: body mass index; SBP: systolic blood pressure; DBP: diastolic blood pressure; SGA: small for gestational age.

\begin{tabular}{|c|c|c|c|c|}
\hline Parameter mean \pm SD & Normal Gestation & Mild PET & Severe PET & P VALUE* \\
\hline Age (years) & $26+/-5$ & $27+/-4$ & $28+/-5$ & 0.36 \\
\hline BMI $\left(\mathrm{kg} / \mathrm{m}^{2}\right)$ & $24.2+/-3.9$ & $25.5+/-3.1$ & $25.3+/-3.2$ & 0.24 \\
\hline $\mathrm{SBP}(\mathrm{mmHg})$ & $115+/-10$ & $145+/-5$ & $159+/-10$ & 0.002 \\
\hline $\mathrm{DBP}(\mathrm{mmHg})$ & $70+/-5$ & $100+/-10$ & $110+/-10$ & 0.002 \\
\hline Serum Uric acid (mg/dL) & $.4 .2+/-1.4$ & $5+/-1.1$ & $6.2+/-1.7$ & 0.001 \\
\hline Serum creatinine $(\mathrm{mg} / \mathrm{dL})$ & $0.5+/-0.07$ & $0.7+/-0.24$ & $0.8+/-0.31$ & 0.002 \\
\hline Glomerular filtration rate $(\mathrm{mL} / \mathrm{min})$ & $130+/-4$ & $110+/-3$ & $100+/-12$ & 0.002 \\
\hline SGOT(U/L) & $22+/-5$ & $34+/-13$ & $44+/-11$ & 0.001 \\
\hline SGPT(U/L) & $23+/-2$ & $31+/-11$ & $36+/-13$ & 0.001 \\
\hline Alkaline phosphatase & $103+/-21$ & $151+/-34$ & $167+/-21$ & 0.001 \\
\hline Serum renalase $(\mathrm{mcg} / \mathrm{mL})$ & $316+/-23$ & $223+/-12$ & $152+/-21$ & 0.001 \\
\hline
\end{tabular}


Journal of Gynecology and Women's Health

\begin{tabular}{|c|c|c|c|}
\hline Proteinuria dipstick method & nil & 1 & 3 \\
\hline Gestational week at delivery & $38.3+/-1.4$ & $35.6 \pm 3.6$ & $34.4+/-2.3$ \\
\hline Birth Weight(g) & $3224 \pm 536$ & $2433 \pm 816$ & $2213+/-952$ \\
\hline SGA (n, \%) & $4(8 \%)$ & $15(30 \%)$ & $16(32 \%)$ \\
\hline Hemoglobin (g/dl) & $12.3 \pm 2.3$ & $11.2 \pm 0.5$ & $10.4+/-0.1$ \\
\hline Platelet count (X 103/mm $\left./ \mathrm{mm}^{3}\right)$ & $254+/-62$ & $151+/-53$ & $132+/-33$ \\
\hline Haematocrit (\%) & $33+/-12$ & $38+/-16$ & 0.005 \\
\hline
\end{tabular}

The demographic and laboratory data of the study population are presented in Table 1 . There were no statistically significant differences in demographic features between normal gestation as control, mild and severe with preeclampsia. Mean serum uric acid levels, serum creatinine, and blood pressure measurements were less in healthy gestations than mild and severe preeclamptic cases (Table 1). In gestations with preeclampsia, BP levels, serum levels uric acid, SGOT, SGPT, alkaline phosphatase and proteinuria/24h were greater than healthy gestations (controls). Hemoglobin indices were slightly lower in gestations with mild and severe PE than healthy gestations (Table 1). Birth weight was statistically significantly lower, and the number of women with SGA infants were significantly higher in gestations with mild and severe preeclampsia than healthy gestations.

In healthy pregnant; renalase levels were statistically significantly higher than in mild and severe preeclampsia cases. (316+/-23 VS, 223+/-12VS, 152+/-21, consecutively, $\mathrm{p}$ value $=0.001)$. Correlation analysis in research cohort displayed that levels of serum renalase had an inverse statistical correlation in a statistically significant manner with systolic and diastolic blood pressure indices; $(\mathrm{p}=0.001, \mathrm{r}=-0.41 ; \mathrm{p}=0.001$, $r=-0.39$ consecutively). Additionally, serum levels of renalase had an inverse correlation with $24 \mathrm{~h}$ protein excretion in urine $(\mathrm{p}=0.004, \mathrm{r}=-0.22)$ on the other hand serum, renalase levels were not correlated statistically with cases age and gestational age.a

\section{Discussion}

The current research study displayed that serum levels of renalase are raised in healthy gestations and reduced in gestations with preeclampsia [12,13]. Renalase is secreted in blood and its serum levels are influenced by three main factors: renal functional performance, renal perfusion levels and catecholamine serum levels. Various recent observational research studies have investigated the correlation between genetic polymorphisms in the renalase gene and the hazardous risk of pathological development of hypertensive disorders. In addition, renalase levels seem to be associated with systolic and diastolic blood pressure levels, glomerular filtration rate and urinary protein excretion in pregnant women with preeclampsia. Since renalase metabolizes catecholamines, it is could be of clinical value in management protocols in disorders associated by raised sympathetic activity [14].

Prior research studies displayed a direct correlation with the glomerular filtration rate and renal mass. Additionally, in the isolated perfused animal kidney model infusions of catecholamine trigger renalase secretion levels in the renal vein. Systemic vascular resistance in human gestation falls significantly as a part of physiological pregnancy changes and leads to a decrease in mean arterial pressure, which causes a compensatory rise in cardiac output levels. A reduced cardiac output level or arterial VD causes a reduction in efficient arterial blood volume indices. This consequently causes the stimulation of the sympathetic system $[15,16]$.

Additionally, renal VD exists concurrently with systemic VD and it is also linked with a $30-50 \%$ rise in renal blood flow levels and glomerular filtration rate indices. It is probable that the revealed elevated serum level of renalase in gestation represents a response to elevated plasma catecholamines and increased GFR. In an experimental study, Zhou et al. displayed that renalase is highly expressed in reproductive/steroidogenic enzymatic system, particularly in ovaries and adrenal gland and renalase serum levels can be augmented by gestation $[17,18]$.

Our current research findings displayed that cases with mild and severe preeclampsia PE gave birth to small for gestational age newborns than clinically healthy gestations. It is well proven from prior research studies that preeclampsia is correlated with raised risk of infants with small for gestational age. This could clarify the correlation displayed in the current research between serum renalase levels and birth weight $[1,5,11]$.

Various research studies on animal and human subjects uncover the pathophysiological fact that renalase regulates blood pressure. Renalase deficiency is correlated with hypertensive disorders and raised sympathetic activity $[3,8]$. Likewise, research studies conducted on cases with resistant hypertensive disorders reveal and display that arterial plasma concentrations of renalase are inversely correlated with systolic blood pressure. Recent research studies have also investigated the role and therapeutic value of recombinant human renalase has a powerful antihypertensive pharmacological impact in rodent animal models of hypertensive disease [4,7].

In another research study conducted in a similar manner by Zehra et al 2016 in which renalase was assayed in healthy Research control study subjects, healthy gestations and gestations having PET matched as regards age, gestational age, within the third gestational trimester. Renalase serum levels were statistically analysed and compared in gestations with and without PET and non-pregnant research control study subjects. Variables of interest linked with renalase serum levels in gestation were also assesed. The research group revealed the following results in which healthy pregnant serum renalase levels were statistically significantly higher than in study subject 
controls. On the other hand, gestations affected by preeclampsia had decreased serum levels of renalase in comparison to healthy study subject control group. renalase serum levels had an inverse correlation with blood pressure measurements and were positively statistically correlated with GFR. The research team concluded that development of preeclamptic pathophysiologic process in pregnancy is associated with alteration and significant changes in renalase serum levels. High blood pressure indices and renal affection that clinically feature this disease are affected at least partially by low serum renalase concentration. These findings are in great jarmony with the current research findings [19].

Our Research study results is in harmony with the findings of the prior research experimental models and clinical data in hypertensive cohorts. Renalase was recommended hypothetically to have a cornerstone role in the pathological development of hypertensive disease and renal dysfunction in general population; therefore this correlation and linkage could be established in hypertensive and renal disorders in gestation [9]. Additionally, low serum renalase levels were correlated with blood pressure indices elevation, and renal insufficiency, presented by proteinuria and low levels of GFR in gestations with PE. The current research study findings uncover the pathophysiological significance of serum renalase in preeclampsia development [10]. Interestingly an ideal research zone is very crucial to develop more inderstanding of renalase levels pathophysiological role in development of hypertensive disorders in pregnanacies, it could be an agent of potential diagnostic and curative value. Additional broader scale research studies are required to clarify the current research study findings.

\section{References}

1. Fischer T, Schobel HB, Frank H, Andreae M, Schneider KT, et al. (2004) Pregnancy-induced sympathetic overactivity: a precursor of preeclampsia. Eur J Clin Invest 34(6): 443- 448.

2. Xu J, Desir GV Renalase (2007) A new renal hormone: its role in health and disease. Curr Opin Nephrol Hypertens 16(4): 373-378.

3. Desir GV (2007) Renalase is a novel renal hormone that regulates cardiovascular function. J Am Soc Hypertens 1(2): 99-103.

4. Hennebry SC, Eikelis N, Socratous F, Desir G, Lambert G, et al. (2010) Renalase, a novel soluble FAD-dependent protein, is synthesized in the brain and peripheral nerves. Mol Psychiatry 15(3): 234-236.
5. Zhou M, Liang T, Wang Y, Jin D, Wang J, et al. (2013) Expression and tissue localization of renalase, a novel soluble FAD-dependent protein, in reproductive/steroidogenic systems. Mol Biol Rep 40(6): 3987-3994.

6. American College of Obstetricians and Gynecologists; Task Force on Hypertension in Pregnancy (2013) Hypertension in pregnancy. Report of the American College of Obstetricians and Gynecologists' Task Force on Hypertension in Pregnancy. Obstet Gynecol 122(5): 1122-1131.

7. McCowan L, Stewart AW, Francis A, Gardosi J (2004) A customised birthweight centile calculator developed for a New Zealand population. Aust NZ J Obstet Gynaecol 44(5): 428-431.

8. Xu J, Li G, Wang P, Velazquez H, Yao X, et al. (2005) Renalase is a novel, soluble monoamine oxidase that regulates cardiac function and blood pressure. J Clin Invest 115(5): 1275-1280.

9. Li G, Xu J, Wang P, Velazquez H, Li Y, et al. (2008) Catecholamines regulate the activity, secretion, and synthesis of renalase. Circulation 117(10): 1277-1282.

10. Gu R, Lu W, Xie J, Bai J, Xu B (2011) Renalase deficiency in heart failure model of rats-a potential mechanism underlying circulating norepinephrine accumulation. PLoS One 6(1): e14633.

11. Tkachenko O, Shchekochikhin D, Schrier RW (2014) Hormones and Hemodynamics in Pregnancy. Int J Endocrinol Metab 12(2): e14098.

12. Moran P, Baylis PH, Lindheimer MD, Davison JM (2003) Glomerular ultrafiltration in normal and preeclamptic pregnancy. J Am Soc Nephrol 14(3): 648-652.

13. Lee TH, Kim JY, Kim M, Wang P, Tang L, et al. (2013) Renalase Protects against Ischemic AKI. J Am Soc Nephrol 24(3): 445-455.

14. Desir GV, Wang L, Peixoto AJ (2012) Human renalase: A review of its biology, function, and implications for hypertension. J Am Soc Hypertens 6(6): 417-426.

15. Zhao Q, Fan Z, He J, Chen S, Li H, Zhang P, Wang L, et al. (2007) Renalase gene is a novel susceptibility gene for essential hypertension: A two stage association study in northern Han Chinese population. J Mol Med 85(8): 877-885.

16. Schlaich M, Socratous F, Eikelis N, Chopra R, Lambert G, et al. (2010) Renalase plasma levels are associated with systolic blood pressure in patients with resistant hypertension J Hypertens 28: e437.

17. Desir GV (2011) Role of renalase in the regulation of blood pressure and the renal dopamine system. Curr Opin Nephrol Hypertens 20(1): 31-36.

18. Baraka A, El Ghotny S (2012) Cardioprotective effect of renalase in 5/6 nephrectomized rats. J Cardiovasc Pharmacol Ther 17(4): 412-416.

19. Zehra Vural Yılmaz, Elif Akkaş, Tolga Ylldırım, Rahmi Yllmaz, Yunus Erdem (2017) A novel marker in pregnant with preeclampsia: renalase. J Matern Fetal Neonatal Med 30(7): 808-813.

\begin{tabular}{l} 
Your next submission with Juniper Publishers \\
will reach you the below assets \\
- Quality Editorial service \\
- Swift Peer Review \\
- Reprints availability \\
- E-prints Service \\
- Manuscript Podcast for convenient understanding \\
- Global attainment for your research \\
- Manuscript accessibility in different formats \\
( Pdf, E-pub, Full Text, Audio) \\
- Unceasing customer service \\
Track the below URL for one-step submission \\
https://juniperpublishers.com/online-submission.php \\
\hline
\end{tabular}

